\title{
Effects of metformin treatment on luteal phase progesterone concentration in polycystic ovary syndrome
}

K.J. Meenakumari², S. Agarwal',

A. Krishna ${ }^{2}$ and L.K. Pandey ${ }^{1}$
${ }^{1}$ Department of Obstetrics and Gynecology, Institute of Medical Sciences, and ${ }^{2}$ Department of Zoology, Banaras Hindu University, Varanasi, India

\section{Correspondence \\ A. Krishna \\ Department of Zoology \\ Banaras Hindu University \\ Varanasi-221005 \\ India \\ Fax: +542-236-8174 \\ E-mail: akrishna_ak@yahoo.co.in}

Research supported by the Department of Science and Technology, India (SP/SO/C-33/99).

Received September 29, 2003 Accepted August 5, 2004

\section{Abstract}

The causes of luteal phase progesterone deficiency in polycystic ovary syndrome (PCOS) are not known. To determine the possible involvement of hyperinsulinemia in luteal phase progesterone deficiency in women with PCOS, we examined the relationship between progesterone, luteinizing hormone ( $\mathrm{LH}$ ) and insulin during the luteal phase and studied the effect of metformin on luteal progesterone levels in PCOS. Patients with PCOS (19 women aged 18-35 years) were treated with metformin (500 mg three times daily) for 4 weeks prior to the test cycle and throughout the study period, and submitted to ovulation induction with clomiphene citrate. Blood samples were collected from control $(\mathrm{N}=5$, same age range as PCOS women) and PCOS women during the late follicular (one sample) and luteal (3 samples) phases and $\mathrm{LH}$, insulin and progesterone concentrations were determined. Results were analyzed by one-way analysis of variance (ANOVA), Duncan's test and Karl Pearson's coefficient of correlation ( $\mathrm{r}$ ). The endocrine study showed low progesterone level $(4.9 \mathrm{ng} / \mathrm{ml})$ during luteal phase in the PCOS women as compared with control $(21.6 \mathrm{ng} / \mathrm{ml})$. A significant negative correlation was observed between insulin and progesterone $(\mathrm{r}=-0.60 ; \mathrm{P}<0.01)$ and between progesterone and $\mathrm{LH}$ $(\mathrm{r}=-0.56 ; \mathrm{P}<0.05)$ concentrations, and a positive correlation $(\mathrm{r}=$ $0.83 ; \mathrm{P}<0.001$ ) was observed between LH and insulin. The study further demonstrated a significant enhancement in luteal progesterone concentration $(16.97 \mathrm{ng} / \mathrm{ml})$ in PCOS women treated with metformin. The results suggest that hyperinsulinemia/insulin resistance may be responsible for low progesterone levels during the luteal phase in PCOS. The luteal progesterone level may be enhanced in PCOS by decreasing insulin secretion with metformin.

\section{Introduction}

Polycystic ovarian syndrome (PCOS) is the most common cause of infertility in women of reproductive age. The syndrome is characterized by infertility, anovulation,
Key words

- Polycystic ovary syndrome

- Metformin

- Luteal phase defect

- Progesterone 
after ovulation induction, they may develop luteal phase defect (LPD) resulting in pregnancy loss (4). The pregnancy rate among PCOS women is only $40-50 \%$ even when other factors are excluded and ovulation induction is successful (5). The deficiency of luteal phase progesterone synthesis and/or action is the leading cause of infertility or spontaneous abortion in cases of LPD (6). The cause of progesterone deficiency during the luteal phase in PCOS patients is not known.

The present study was carried out in an attempt to elucidate the cause of progesterone deficiency during the luteal phase in women with PCOS, with two main objectives. First, to determine whether low progesterone concentrations in PCOS women during the luteal phase is correlated with circulating LH and insulin concentrations, and second, to determine whether metformin can improve luteal progesterone concentrations in PCOS women submitted to ovulation induction with clomiphene citrate.

\section{Subjects and Methods}

Subjects

A total of 24 subjects (19 women with PCOS and 5 controls) 18-35 years of age attending the fertility clinic of the Department of Obstetrics and Gynecology, Sir Sunderlal Hospital, Banaras Hindu University, India, were evaluated. The diagnosis of PCOS was made according to the criteria of the 1990 National Institutes of Health Conference. These include oligomenorrhea, hyperandrogenism, presence of 8 or more cystic follicles (about $10 \mathrm{~mm}$ in diameter) on ultrasound, and the absence of other endocrine disorders (congenital adrenal hyperplasia, hyperprolactinemia, thyroid dysfunction, and androgen secreting tumors) (7). Follicular growth, ovulation and development of corpus luteum were monitored by transvaginal ultrasonography. Ovulation documented by ultrasound was later confirmed by serum progesterone levels. The body mass index (BMI) of control subjects $(21.7 \pm 0.9)$ was not significantly different from that of PCOS patients $(22.6 \pm 0.56)$. The control subjects were not on any regular medication and had a history of regular menstrual cycles and normal reproduction.

\section{Collection of blood samples}

Venous blood ( $\sim 5 \mathrm{ml})$ was collected between 8:00 and 10:00 am after an overnight fast during the follicular and luteal phase of the cycle. The blood samples were collected during: a) the late follicular phase, b) early luteal phase (day 1-4 after ovulation), c) mid-luteal phase (day 5-9 after ovulation), and d) late luteal phase (day 10-14 after ovulation). Serum was immediately separated and stored at $-20^{\circ} \mathrm{C}$ until the time for radioimmunoassay (RIA). The recommended test for the determination of LPD is a midluteal phase single serum progesterone level $<10 \mathrm{ng} / \mathrm{ml}$ or the sum of three serum progesterone levels $<30 \mathrm{ng} / \mathrm{ml}$ (8).

\section{Ultrasonographic analysis}

Ultrasound parameters such as peripheral arrangement of cysts in the ovary, stromal hyperplasia and ovarian enlargement were used to define PCOS. Follicular monitoring was performed in all patients to detect a preovulatory follicle, the day of ovulation and the development of the corpus luteum $(8,9)$. The presence of a dominant follicle (>16-18 $\mathrm{mm}$ in diameter) and of an echogenic mass projecting into the follicle were the potential signs of impending ovulation.

\section{Experimental protocols}

The Ethics Committee of the Banaras Hindu University approved the study and all subjects gave written informed consent to participate. 


\section{Experiment I}

Serum samples collected from control and PCOS subjects during the follicular and luteal phases were assayed for progesterone, LH and insulin by RIA.

\section{Experiment 2}

The PCOS patients were randomly divided into three groups as follows: i) natural cycle $(\mathrm{N}=7, \mathrm{BMI}=22.4 \pm 1.13)$. No treatment was given. ii) PCOS subjects on clomiphene citrate $(\mathrm{N}=7, \mathrm{BMI}=22.01 \pm 0.93)$. The patients were given $50 \mathrm{mg} /$ day clomiphene citrate from day 5 to 9 during the test cycle. iii) PCOS subjects on metformin plus clomiphene citrate $(\mathrm{N}=5, \mathrm{BMI}=23.72 \pm$ $0.71)$. The patients were given metformin (500 mg three times daily starting four weeks prior to the test cycle). During the test cycle both clomiphene citrate $(50 \mathrm{mg} /$ day from day 5 to 9) and metformin (500 mg three times daily) were given.

Normal healthy women with regular menstrual cycles were used as controls $(\mathrm{N}=5$, $\mathrm{BMI}=21.72 \pm 0.91)$. Blood samples from all four groups were collected during the follicular and luteal phases for hormone assay.

\section{Hormone assay}

Progesterone assay. A progesterone RIA kit was purchased from ICN Biomedicals Inc., Costa Mesa, CA, USA. Twenty-five microliters of each standard and the samples were added to anti-progesterone-coated tubes. Progesterone $\mathrm{I}^{125}(1 \mathrm{ml})$ was then added to each tube and the tubes were incubated at $37^{\circ} \mathrm{C}$ for $60 \mathrm{~min}$. After incubation the tubes were decanted and the empty tubes were counted in a Beckman gamma counter (Geneva, Switzerland). The concentration of progesterone in the samples was deduced from extrapolation of the standard curve. All tubes for progesterone were assayed together and intra-assay variation was less than $10 \%$.
Insulin assay. An insulin RIA kit was purchased from Bhabha Atomic Research Center, Mumbai, India. Serum samples $(0.1 \mathrm{ml})$ were added to $12 \times 75 \mathrm{~mm}$ tubes. Assay buffer (300 $\mu 1)$ and $100 \mu$ guinea pig anti-human insulin antiserum were added to the $100-\mu 1$ plasma samples and standards. After mixing gently, all tubes were incubated overnight at $4^{\circ} \mathrm{C} .{ }^{125} \mathrm{I}-$ labeled insulin $(100 \mu \mathrm{l})$ was added to all tubes. The tubes were then mixed gently and incubated for $3 \mathrm{~h}$ at room temperature. Secondary antibody (100 $\mu 1$; anti-guinea pig $\operatorname{IgG})$ and 1.0 $\mathrm{ml}$ of polyethylene glycol solution were added to all tubes except in the tube for total count. All tubes were vortexed, kept at room temperature for $20 \mathrm{~min}$ and then centrifuged at 1500 $g$ for $20 \mathrm{~min}$. The supernatant was discarded without disturbing the precipitate. Average counts per minute were carried out for all tubes in duplicate using a Beckman gamma counter. Standards (7.5-200 $\mu \mathrm{IU} / \mathrm{ml})$, zero standard and blank tubes were processed along with the samples. All samples were run in a single assay. The intra-assay coefficient of variation was less than $7.8 \%$.

LH assay. An LH RIA kit was purchased from Bhabha Atomic Research Center. Serum samples and standards (100 $\mu \mathrm{l}$ each) were diluted with $200 \mu 1$ of assay buffer and $100 \mu \mathrm{l}$ of human LH antiserum and $100 \mu \mathrm{l}$ of ${ }^{125}$ I-labeled hLH was added to each tube. The tubes were then vortexed and incubated at $37^{\circ} \mathrm{C}$ for $2 \mathrm{~h}$. Anti-rabbit $\operatorname{IgG}(0.1 \mathrm{ml})$ and $1.0 \mathrm{ml}$ polyethyleneglycol were added simultaneously to all tubes except in the tube for total count, vortexed and kept at room temperature for $20 \mathrm{~min}$. The tubes were then centrifuged at $1500 \mathrm{~g}$ for $20 \mathrm{~min}$. After centrifugation the supernatants were discarded and precipitates were counted (per minute) in a gamma scintillation counter (Beckman). Standards (5.0-100 mIU/ml), zero standard and blank tubes were also processed with the samples. LH concentration was deduced from the standard curve. All tubes for LH were assayed together and intra-assay variation was less than $10 \%$. 


\section{Statistical analysis}

Results were analyzed by one-way analysis of variance (ANOVA), Duncan's test and Pearson's correlation coefficient (r).

\begin{tabular}{|c|c|c|c|c|}
\hline Cycle phase & $\begin{array}{l}\text { Control } \\
(\mathrm{N}=5)\end{array}$ & $\begin{array}{l}\text { PCOS women } \\
\text { on a natural cycle } \\
(\mathrm{N}=7)\end{array}$ & $\begin{array}{l}\text { PCOS women } \\
\text { on clomiphene } \\
\text { citrate } \\
(N=7)\end{array}$ & $\begin{array}{l}\text { PCOS women } \\
\text { on clomiphene } \\
\text { citrate }+ \text { metformin } \\
(N=5)\end{array}$ \\
\hline Follicular & $1.24 \pm 0.13$ & $1.74 \pm 0.433$ & $1.33 \pm 0.15$ & $1.34 \pm 0.12$ \\
\hline Early luteal & $13.80 \pm 0.13$ & $4.06 \pm 1.92^{a}$ & $5.04 \pm 0.16^{a}$ & $9.64 \pm 3.20^{a b c}$ \\
\hline Mid-luteal & $23.20 \pm 5.15$ & $5.50 \pm 4.07^{a}$ & $10.00 \pm 4.10^{a}$ & $23.30 \pm 8.10^{b c}$ \\
\hline Late luteal & $27.80 \pm 4.30$ & $5.13 \pm 3.16^{a}$ & $6.37 \pm 1.78^{a}$ & $17.98 \pm 4.90^{\mathrm{abc}}$ \\
\hline $\begin{array}{l}\text { Mean luteal } \\
\text { phase }\end{array}$ & $21.60 \pm 2.83$ & $4.90 \pm 1.75^{a}$ & $7.13 \pm 1.60^{a}$ & $16.97 \pm 3.43^{b c}$ \\
\hline
\end{tabular}

PCOS patients received $50 \mathrm{mg} /$ day clomiphene citrate from day 5 to day 9 during the cycle and $500 \mathrm{mg}$ metformin three times daily starting 4 weeks prior to the test cycle. Data are reported as means \pm SEM in $\mathrm{ng} / \mathrm{ml}$. The number of cases studied is given in parentheses. Values were significantly different $(P<0.05)$ by Duncan's test compared with: ${ }^{a}$ control, bPCOS women on a natural cycle, and ${ }^{\mathrm{CPCOS}}$ women treated with clomiphene citrate.
Table 2. Serum LH levels in different phases of the menstrual cycle for women with polycystic ovary syndrome (PCOS) on a natural cycle, women with PCOS treated with clomiphene citrate and women with PCOS treated with clomiphene citrate plus metformin.

\begin{tabular}{|c|c|c|c|c|}
\hline Cycle phase & $\begin{array}{l}\text { Control } \\
(\mathrm{N}=5)\end{array}$ & $\begin{array}{l}\text { PCOS women } \\
\text { on a natural cycle } \\
(\mathrm{N}=7)\end{array}$ & $\begin{array}{l}\text { PCOS women } \\
\text { on clomiphene } \\
\text { citrate } \\
(\mathrm{N}=7)\end{array}$ & $\begin{array}{c}\text { PCOS women } \\
\text { on clomiphene } \\
\text { citrate + metformin } \\
\quad(N=5)\end{array}$ \\
\hline Follicular & $14.5 \pm 1.29$ & $24.37 \pm 1.98$ & $22.63 \pm 1.90$ & $24.14 \pm 1.22$ \\
\hline Early luteal & $12.34 \pm 0.99$ & $28.37 \pm 0.99^{a}$ & $28.44 \pm 1.07^{a}$ & $21.36 \pm 1.34^{a}$ \\
\hline Mid-luteal & $11.60 \pm 1.43$ & $22.11 \pm 1.25^{a}$ & $25.00 \pm 1.98 a$ & $18.80 \pm 1.50^{\mathrm{ac}}$ \\
\hline Late luteal & $5.60 \pm 0.84$ & $14.57 \pm 1.36^{a}$ & $25.14 \pm 2.30 \mathrm{abc}$ & c $\quad 17.40 \pm 1.75^{\mathrm{ac}}$ \\
\hline $\begin{array}{l}\text { Mean luteal } \\
\text { phase }\end{array}$ & $9.85 \pm 0.98$ & $21.69 \pm 1.43^{a}$ & $26.20 \pm 1.03^{a}$ & $19.19 \pm 0.93^{a}$ \\
\hline
\end{tabular}

The doses and duration of treatment with clomiphene citrate and metformin are given in the legend to Table 1. Data are reported as means \pm SEM in IU/I. The number of cases studied is given in parentheses. Values were significantly different $(P<0.05)$ by Duncan's test compared with: ${ }^{a}$ control, bPCOS women on a natural cycle, and ${ }^{\mathrm{CPCOS}}$ women treated with clomiphene citrate.

\section{Results}

Experiment 1. Serum progesterone, LH and insulin concentration during the luteal phase in control and PCOS women

Serum progesterone, LH and insulin concentrations during the follicular and luteal phases for the control and PCOS women are shown in Tables 1-3. An increase in progesterone concentration from the follicular to the luteal phase was observed both in the control and PCOS women. The control women showed consistently high luteal progesterone, whereas PCOS women showed significantly lower concentrations. In contrast to progesterone concentration, both $\mathrm{LH}$ and insulin concentrations were consistently higher during the follicular and luteal phases in PCOS women compared to control. The correlation coefficient was calculated to determine the relationship between progesterone, LH and insulin concentrations based on mean values obtained during the luteal phase. The results showed a negative correlation between progesterone and insulin (Figure $1 ; \mathrm{r}=-0.60 ; \mathrm{P}<0.01)$, and progesterone and LH (Figure 2; $\mathrm{r}=-0.56 ; \mathrm{P}<0.05$ ), whereas insulin showed a positive correlation with LH (Figure 3; $r=0.83 ; \mathrm{P}<0.001$ ).

\section{Experiment 2. Effect of metformin on luteal progesterone, $\mathrm{LH}$ and insulin concentrations in PCOS women submitted to ovulation induction with clomiphene citrate}

The results of this experiment are also shown in Tables 1-3. PCOS women on a natural cycle treated with clomiphene citrate and with clomiphene citrate plus metformin showed no statistically significant difference in progesterone, LH or insulin concentrations during the late follicular phase. However, a significant increase in luteal progesterone concentration occurred in PCOS women treated with metformin compared with the PCOS women on a natural cycle and 
Table 3. Serum insulin in different phases of the menstrual cycle for women with polycystic ovary syndrome (PCOS) on a natural cycle, women with PCOS treated with clomiphene citrate and women with PCOS treated with clomiphene citrate plus metformin.

\begin{tabular}{lcccc}
\hline Cycle phase & Control $(\mathrm{N}=5)$ & $\begin{array}{c}\text { PCOS women } \\
\text { on a natural cycle } \\
(\mathrm{N}=7)\end{array}$ & $\begin{array}{c}\text { PCOS women on } \\
\text { clomiphene citrate } \\
(\mathrm{N}=7)\end{array}$ & $\begin{array}{c}\text { PCOS women on } \\
\text { clomiphene citrate } \\
+ \text { metformin }(\mathrm{N}=5)\end{array}$ \\
\hline Follicular & $9.36 \pm 0.86$ & $25.29 \pm 1.98$ & $22.44 \pm 2.03$ & $24.88 \pm 1.73$ \\
Early luteal & $10.56 \pm 0.79$ & $21.43 \pm 1.46^{\mathrm{a}}$ & $19.99 \pm 1.40^{\mathrm{a}}$ & $23.44 \pm 1.58^{\mathrm{a}}$ \\
Mid-luteal & $10.48 \pm 0.75$ & $20.54 \pm 0.96^{\mathrm{a}}$ & $19.79 \pm 0.74^{\mathrm{a}}$ & $14.72 \pm 1.60^{\mathrm{abc}}$ \\
Late luteal & $11.34 \pm 0.82$ & $23.07 \pm 1.43^{\mathrm{a}}$ & $25.80 \pm 1.24^{\mathrm{a}}$ & $18.44 \pm 1.12^{\mathrm{abc}}$ \\
Mean luteal phase & $10.79 \pm 0.43$ & $21.68 \pm 0.75^{\mathrm{a}}$ & $21.86 \pm 0.89^{\mathrm{a}}$ & $18.87 \pm 1.22^{\mathrm{a}}$
\end{tabular}

The doses and duration of treatment with clomiphene citrate and metformin are given in the legend to Table 1. Data are reported as means \pm SEM in $\mu / \mathrm{I} / \mathrm{l}$. The number of cases studied is given in parentheses. Values were significantly different $(P<0.05)$ by Duncan's test compared with: ${ }^{a}$ control, bPCOS women on a natural cycle, and ${ }^{\mathrm{P} C O S}$ women treated with clomiphene citrate.
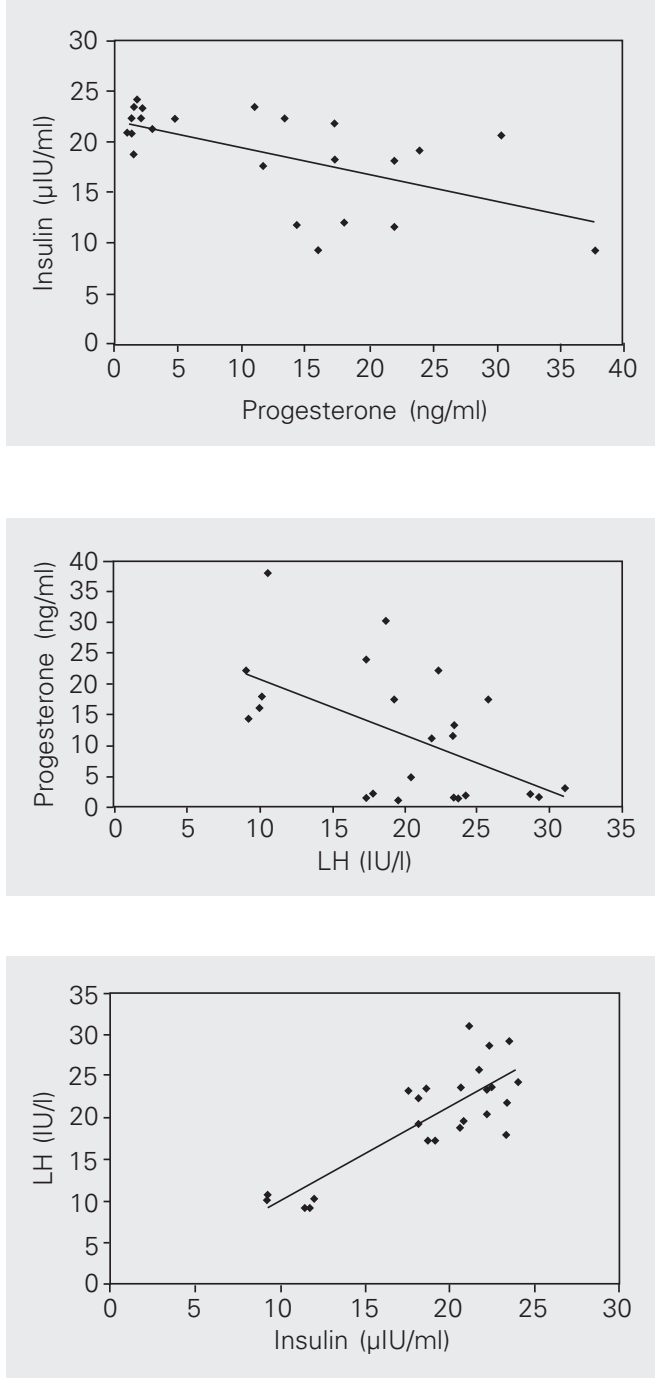

Figure 1. Correlation between serum insulin and progesterone during the luteal phase in women with polycystic ovary syndrome $(N=19)$ and controls $(N=5)$. $r=-0.60 ; P<0.01$ (Pearson's correlation coefficient test).

Figure 2. Correlation between serum luteinizing hormone $(\mathrm{LH})$ and progesterone during the luteal phase in women with polycystic ovary syndrome $(\mathrm{N}=19)$ and controls $(N=5) . r=-0.56$; $P<0.05$ (Pearson's correlation coefficient test).

Figure 3. Correlation between serum insulin and luteinizing hormone (LH) concentration in women with polycystic ovary syndrome $(N=19)$ and controls $(N=5)$. $r=0.83 ; P<0.001$ (Pearson's correlation coefficient test). 
with PCOS women treated with only clomiphene citrate. During the mid- and late-luteal phases an increase in progesterone concentration was found in the metformin-treated group. LH and insulin concentrations declined during the mid- and late-luteal phases in the metformin-treated group. The individual evaluation of progesterone concentration showed LPD in 6 of $7(90 \%)$ cases of PCOS on a natural cycle and in 4 of $7(60 \%)$ cases of PCOS given only clomiphene citrate, but only 1 of $5(20 \%)$ cases of PCOS showed LPD when treated with metformin plus clomiphene citrate.

\section{Discussion}

The present study showed a significantly lower progesterone concentration in PCOS women compared with control during the luteal phase. This low progesterone concentration during the luteal phase may be responsible for early pregnancy losses in PCOS women $(6,10)$. In the present study, an attempt was made to determine the factor(s) responsible for low progesterone synthesis during the luteal phase in PCOS women.

In contrast to the previous studies showing decreased LH levels or bioactivity as a major factor responsible for the reduced luteal progesterone levels in women with LPD, the present study showed LH hypersecretion in PCOS women during the luteal phase. LH hypersecretion is frequently found in women with PCOS during the follicular phase and is one of the important factors which impair fertility in these women (11). Regan et al. (12) demonstrated that $65 \%$ of pregnancies in women with LH hypersecretion result in spontaneous abortion, although a recent study from their laboratory failed to show any significant correlation between elevated serum $\mathrm{LH}$ concentration and miscarriage rate in patients with PCOS (13). Homburg et al. (4) and Sagle et al. (10) provided further evidence for the adverse effect of high LH in early pregnancy loss in PCOS women, al- though the mechanism by which LH causes recurrent abortion is not known. In the present study high LH levels showed a negative correlation with progesterone level during the luteal phase in PCOS women, possibly implying that low progesterone levels may be associated with LH hypersecretion in this syndrome. It has been hypothesized that high LH concentrations may stimulate the high androgen synthesis observed in PCOS (14), using progesterone as a precursor. It may also be possible that LH-induced hyperandrogenism suppresses progesterone synthesis, although these possibilities need further confirmation. The positive correlation between LH and insulin observed in the present study suggests that high LH levels in PCOS women may be due to hyperinsulinemia/insulin resistance. Several studies using metformin, a commonly employed insulinsensitizing agent, have shown reduced LH levels in PCOS women, suggesting an enhancing influence of insulin on LH secretion $(15,16)$.

In the present study, a high insulin level was also observed in the PCOS women during the luteal phase, showing a negative correlation with progesterone concentration. Insulin resistance with compensatory hyperinsulinemia is a prominent feature of PCOS, adversely affecting follicular development and ovulation by increasing intra-ovarian androgen production (17). Early trials of metformin in PCOS showed an improvement in insulin metabolism and a reduction in circulating androgen levels (18). Metformin as pretreatment and co-treatment with clomiphene citrate seems to be successful in normalizing menstrual irregularities, perhaps by sensitizing follicles to follicle-stimulating hormone. Therefore, metformin alone or together with clomiphene citrate has been proposed as a treatment for ovulation induction in infertile women with PCOS (19-21).

To our knowledge, the present study is the first report demonstrating a significant enhancement in luteal progesterone concen- 
tration in PCOS women by metformin treatment. In a recent study, several previously infertile women with the PCOS who were treated with metformin for 6 months became pregnant (22). Continued metformin treatment reduced the rates of pregnancy loss in PCOS women $(23,24)$, although another study did not support this result (25). However, the earlier studies were uncontrolled and were not specifically designed to monitor variation in progesterone concentration following metformin treatment. The results of the present study suggest that the beneficial effect of metformin treatment during pregnancy could be due to the improvement in progesterone synthesis with the decline in insulin level and/or insulin resistance.

Further studies are required to determine the mechanism by which insulin adversely affects progesterone production during the luteal phase in the PCOS. It has been previously shown that insulin suppresses progesterone production by granulosa cells collected from women with PCOS but not from normal women (26). It is also possible that insulin might be acting by regulating $\mathrm{LH}$ secretion. Insulin receptors have been identified in human pituitary tissue (27) and insulin increases the release of LH by cultured rat pituitary cells (28). We also showed a significant positive relationship between insulin and LH concentration during the luteal phase.
The present study has certain limitations. The luteal progesterone concentration was measured as the final outcome, but it is not clear whether the increased progesterone levels would successfully regulate pregnancy. It is not clear in the present study whether the effect of insulin on progesterone is direct or is mediated by LH release. It is well known that insulin can enhance LH release (17). Furthermore, the present study failed to show whether hyperinsulinemia or insulin resistance is more important in lowering progesterone levels. Last, it is not clear whether the improved progesterone levels in women treated with metformin were also accompanied by a decrease in androgen levels.

The present study was undertaken to determine the endocrine factors responsible for LPD in PCOS women. An endocrine study showed low progesterone, but high LH and insulin concentrations during the luteal phase in PCOS women compared to control. Combined treatment with clomiphene and metformin increased luteal progesterone concentrations and decreased insulin and $\mathrm{LH}$ concentrations in PCOS women. We suggest that hyperinsulinemia and/or insulin resistance may be responsible for luteal phase progesterone deficiency in PCOS. Further studies are required to determine the mechanism by which insulin affects luteal progesterone.

\section{References}

1. Morales AJ, Laughlin GA, Butzow T, Maheshwari H, Bauman G \& Yen SSC (1996). Insulin, somatotropic, and luteinizing hormone axes in lean and obese women with polycystic ovary syndrome: Common and distinct features. Journal of Clinical Endocrinology and Metabolism, 81: 2854-2864.

2. Dunaif A (1999). Insulin action in the polycystic ovary syndrome. Endocrinology and Metabolism Clinics of North America, 28: 341357.

3. Dunaif A (1997). Insulin resistance and the polycystic ovary syndrome: mechanism and implications for pathogenesis. Endocrine Reviews, 18: 774-800.

4. Homburg R, Armar NA, Eshel A, Adams J \& Jacobs HS (1988). Influence of serum luteinising hormone concentrations on ovula- tion, conception, and early pregnancy loss in polycystic ovary syndrome. British Medical Journal, 297: 1024-1026.

5. Adashi EY (1986). Clomiphene citrate-initiated ovulation: a clinical update. Seminars in Reproductive Endocrinology, 4: 255-276.

6. Soules MR, McLachlan RI, Marit EK, Dahl KD, Cohen NL \& Bremner WJ (1989). Luteal phase deficiency: characterization of reproductive hormones over the menstrual cycle. Journal of Clinical Endocrinology and Metabolism, 69: 804-812.

7. Dunaif A \& Thomas A (2001). Current concepts in the polycystic ovary syndrome. Annual Review of Medicine, 52: 401-419.

8. Jordon J, Craig K, Clifton DK \& Soules MR (1994). Luteal phase defect: the sensitivity and specificity of diagnostic methods in common clinical use. Fertility and Sterility, 62: 54-62. 
9. Chang RJ \& Katz SE (1999). Diagnosis of polycystic syndrome. Endocrinology and Metabolism Clinics of North America, 28: 397408.

10. Sagle M, Bishop K, Ridley N, Alexander FM, Michel M, Bonney RC, Beard RW \& Franks S (1988). Recurrent early miscarriage and polycystic ovaries. British Medical Journal, 297: 1027-1028.

11. Berga SL, Guzick DS \& Winters SJ (1993). Increased luteinizing hormone and alpha subunit secretion in women with hyperandrogenic anovulation. Journal of Clinical Endocrinology and Metabolism, 77: 895-901.

12. Regan L, Owen EJ \& Jacobs HS (1990). Hypersecretion of luteinising hormone, infertility, and miscarriage. Lancet, 336: 1141-1144.

13. Rai R, Backos M, Rushworth F \& Regan L (2000). Polycystic ovaries and recurrent miscarriages - a reappraisal. Human Reproduction, 15: 612-615.

14. Deaton JL, Dempsey RA \& Miller KA (1996). Serum from women with polycystic ovary syndrome inhibits fertilization and embryo development in the murine in vitro fertilization model. Fertility and Sterility, 65: 1224-1228.

15. Velazquez EM, Mendoza SG, Hamer T, Sosa F \& Glueck CJ (1994). Metformin therapy in polycystic ovary syndrome reduces hyperinsulinemia, insulin resistance, hyperandrogenemia and systolic blood pressure, while facilitating normal menses and pregnancy. Metabolism, 43: 647-654.

16. Arroyo A, Laughlin GA, Morales AJ \& Yen SSC (1997). Inappropriate gonadotropin secretion in polycystic ovary syndrome: Influence of adiposity. Journal of Clinical Endocrinology and Metabolism, 82: 3728-3733.

17. Nestler JE \& Jakubowicz DJ (1996). Decreases in ovarian cytochrome P450c $17 \alpha$ activity and serum free testosterone after reduction of insulin secretion in polycystic ovary syndrome. New England Journal of Medicine, 335: 617-623.

18. Harborne L, Fleming R, Lyall H, Norman J \& Sattar N (2003). Descriptive review of the evidence for the use of metformin in polycystic ovary syndrome. Lancet, 361: 1894-1901.
19. Kim LH, Taylor AE \& Barbieri RL (2000). Insulin sensitizers and polycystic ovary syndrome: can a diabetes medication treat infertility? Fertility and Sterility, 73: 1097-1098.

20. Nestler JE, Jakubowicz DJ, Evans WS \& Pasquali R (1998). Effects of metformin on spontaneous and clomiphene induced ovulation in the polycystic ovary syndrome. New England Journal of Medicine, 338: 1876-1880.

21. Nestler JE, Stovall D, Akhter N, luomo MJ \& Jakubowicz DJ (2002). Strategies for the use of insulin-sensitizing drugs to treat infertility in women with polycystic ovary syndrome. Fertility and Sterility, 77: 209-215.

22. Velazquez EM, Acosta A \& Mendoza S (1997). Menstrual cyclicity after metformin therapy in polycystic ovary syndrome. Obstetrics and Gynecology, 16: 392-395.

23. Glueck CJ, Phillips H, Cameron D, Sieve-Smith L \& Wang P (2001). Continuing metformin throughout pregnancy in women with polycystic ovary syndrome appears to safely reduce first trimester spontaneous abortion: a pilot study. Fertility and Sterility, 75: 46-52.

24. Jakubowicz DJ, Inorno MJ, Jakubowicz S, Roberts KA \& Nestler JE (2002). Effects of metformin on early pregnancy loss in the polycystic ovary syndrome. Journal of Clinical Endocrinology and Metabolism, 87: 524-529.

25. Heard MJ, Pierce A, Carson SA \& Buster JE (2002). Pregnancies following use of metformin for ovulation induction in patients with polycystic ovary syndrome. Fertility and Sterility, 77: 669-673.

26. Erickson GF, Magoffin D, Garzo VG, Cheung AP \& Chang R (1992). Granulosa cells of polycystic ovaries: Are they normal or abnormal? Human Reproduction, 7: 292-299.

27. Unger JW, Livingston JN \& Moss AM (1991). Insulin receptors in the central nervous system: localization, signaling mechanisms and functional aspects. Progress in Neurobiology, 36: 343-362.

28. Adashi EY, Hsueh AJW \& Yen SSC (1981). Insulin enhancement of luteinizing hormone and follicle-stimulating hormone release by cultured pituitary cells. Endocrinology, 108: 1441-1449. 